\title{
ROLE OF DECOMPRESSIVE CRANIECTOMY IN PATIENTS WITH TRAUMATIC
} INTRACRANIAL HEMATOMAS.

\section{Neurosurgery \\ Dr. Amar Nath* \\ Assistant Professor, Neurosurgery Department, PGIMS, Rohtak. *Corresponding Author}

\section{ABSTRACT}

Aim - The study done to evaluate the role of decompressive craniectomy in patients with traumatic intracranial hematomas.

Introduction- Although decompressive craniectomy for traumatic brain injury is very effective procedure in patients with raised intracranial pressure refractory to medical measures, its effect on clinical outcome is still unclear because of both positive as well as negative impact of procedure. As after decompressive craniectomy, clinical outcome becomes mainly dependent on primary head injury as secondary injury is prevented by decompressive craniectomy and beneficial effect of decompressive craniectomy is partially neutralized by complications associated with it to a small but significant extent

Patients and method - we retrospectively analysed 72 patients operated in last five years for traumatic intracranial hematomas by decompressive craniotomy. We followed practice of large craniotomy and evacuation of hematomas in last five years in properly selected patients and reserving craniectomy as second procedure in patients in whom patient did not improve radiologically/clinically after craniotomy.

Results - In 61 out of 72 patients operated by decompressive craniotomy, there has been significant improvement in GCS of patients and none of patients needed decompressive craniectomy.

\section{KEYWORDS}

Decompressive Craniectomy, Traumatic Intracranial Hematoma, Intracranial Pressure.

\section{INTRODUCTION}

Traumatic brain injury remains a significant public health problem worldwide due to increasing incidence of motor vehicular accidents in both developing as well as developed countries. It is leading cause of death and disability among productive age group around the globe. The main pathogenetic factor are Brain swelling and resulting intracranial hypertension in addition to primary brain injury. Decompressive craniectomy $\{D C\}$ refers to removal of large bone flap of enough size \{around $15 * 10 \mathrm{~cm}$ \} reaching up to frontal and temporal base and opening dura in order to evacuate hematoma and alleviate effect of intracranial hypertension followed by lax duraplasty and reposition of bone flap in abdominal subcutaneous pouch. Common indications are traumatic head injuries, spontaneous intracranial hematomas and malignant middle cerebral infarcts ${ }^{1,2,3}$. Although decompressive craniectomy effectively results in improvement of intracranial pressure $\{I C P\}$ resulting in improvement of cerebral blood flow ${ }^{4,5,6,7}$, final prognosis of patient depends on presenting GCS of patient which in turn is dependent on primary brain injury. Provided that DC is done timely before secondary damage has occurred and all systemic factors are managed well. Since its introduction, DC is very commonly used procedure in management of patients with intractable intracranial pressure. And its wide spread use has pulled attention to complications related to procedure itself to variable but very significant extent. Suboptimal DC causes external brain herniation and brain necrosis due to direct impingement of brain cortex and venous blockage by craniectomy margins where as large DC causes various complications like hematoma formation below flap ${ }^{8,9,10}$, contralateral hematoma ${ }^{11,12,1}$ increase in size of contusions ${ }^{10,11,13}$, wound dehiscence and CSF leakage ${ }^{9}$, changes in CSF dynamics like subdural hygroma \{interhemispheric as well as contralateral $\}^{10,12,15,16,17}$ and hydrocephalus $^{8,9,14,15,16}$, external herniation of brain, syndrome of trephined $^{16,18,19}$, paradoxical herniation and late complications like personality changes. These complications may lead to clinical deterioration and may require additional interventions like burr hole aspiration for subdural hygroma and ventriculoperitoneal shunting for hydrocephalus and finally cranioplasty and subsequent complications related to ventriculoperitoneal shunting and cranioplasty leading to increased morbidity of patient. Due to high incidence of associated complications, we are very restrictive in use of this procedure in patients of traumatic acute subdural hematoma $\{\mathrm{SDH}\}$ and frontotemporal contusions in whom surgical removal of pathogenetic lesion is possible resulting in decrease in cerebral edema with resultant decrease of ICP to level that can be managed medically.

\section{PATIENTS AND METHOD -}

We retrospectively analyzed results of 72 patients operated in last five years in our unit. We included patients between age group of 16-60 yrs. with history of trauma in our study. Only patients with significant thickness unilateral acute subdural hematoma $\{\mathrm{SDH}\}$ with midline shift of more than eight to ten $\mathrm{mm}$ and patients with frontal and temporal contusions having significant compression on brain stem are included in study. Patients with diffuse brain injury and patients with brain stem contusion and contusions on other eloquent areas of brain and patients with bilateral dilated pupils, GCS score less than five are excluded from study. Also, patients with associated chest injury are excluded from study. We did not have ICP monitoring facility in our institute and we relied only on clinical as well as radiological monitoring \{CT scan finding \} of patient for decision making. Following protocol was used in management of selected patients according to above criteria. Once patient is decided for operative intervention, he is taken for surgery as early as possible. We elevate wide craniotomy flap reaching from near midline to frontal and temporal base and reaching behind parietal eminence, opening dura in curvilinear fashion along craniotomy margin with base towards temporal base and evacuation of SDH and frontal and temporal contusions followed by closure in two layers leaving the dura open and replacing bone flap loosely. Antibiotics with anticonvulsants and antiedema are added in postoperative treatment. Twenty four hr. post operatively, CT scan is done or as required according to clinical assessment. We kept craniectomy as salvage procedure if postoperative $\mathrm{CT}$ is indicative of persistence or increase of midline shift.

\section{RESULTS -}

There were 46 male patients out of 72 . All patients presented with history of road traffic accident. There were $20\{28 \%\}$ patients with acute SDH only, $36\{50 \%\}$ patients were having frontal or temporal contusions associated with acute SDH and $16(22 \%)$ patients were having frontal/temporal contusions only. We preferred GCS assessment by motor score. There were $22\{30 \%\}$ patients presented with GCS between five to seven $\left\{\mathrm{M}_{3}\right.$ and $\left.\mathrm{M}_{4}\right\}$ and $43\{60 \%\}$ patients with GCS between eight to ten $\left\{\mathrm{M}_{5}\right\}$ and seven $\{10 \%\}$ patients presented with GCS between 11-12 $\left\{\mathrm{M}_{5}\right\}$. Fifty two $\{72 \%\}$ of the patients were operated within $24 \mathrm{hrs}$. of injury and rest of patients were started conservative treatment. Out of which, $14\{19 \%\}$ patients were operated within $72 \mathrm{hrs}$. and rest six $\{8 \%\}$ were operated five days post injury after clinical (decreasing motor score) and radiological deterioration (in form of increasing subfalcine or uncal herniation) is documented. Post operatively, improvement in GCS is seen in 43 $\{60 \%\}$ patients within $72 \mathrm{hrs}$. of surgery and in $59\{84 \%\}$ patients within seven days of surgery. Forty eight $\{67 \%\}$ patients were completely conscious at time of discharge \{average two weeks $\}$ and total $60\{83 \%$ p patients were conscious at second follow up \{around one month $\}$. None of patient needed craniectomy. Eight patients developed wound infection. Out of which, three patients developed bone flap infection. In 30 patients sub-galeal collection occurred. In one patient there was subdural hygroma in addition to subgaleal collection. No hydrocephalus seen in any patient. Eight patients died. Six due to poor chest condition and two due to repeated seizure episodes.

\section{DISCUSSION-}

There are two mechanisms of pathogenesis of head injury. In our selected group of pts, it is mainly by focal injury in which there is 
hematoma formation subduraly or frontal and temporal contusion occurs which by its mass effect added by mass effect from consequent brain edema causes shifting of brain and effacement of ipsilateral lateral ventricles and basal cisterns causing compression of cerebral peduncles and third nerve $\{$ Fig 1A $\}$. Further increase in effacement of basal cisterns leads to opposite ventricular dilatation and increase in brain stem compression by both herniating temporal horns leading to fall in GCS level of patient $\{$ Fig 1B $\}$. Early craniotomy followed by evacuation of pathogenetic lesion with frontal or temporal lobectomy if required and leaving dura open and putting back bone flap loosely leads to effective decompression and provides limited increase in intra cranial capacity resulting in decrease in ICP added by continuous medical management consisting of antiedema leads to opening of basal cisterns and decompression of

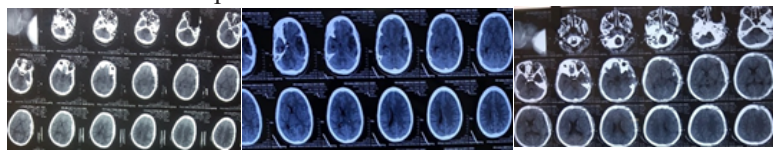

A 21 years female patient presented with history of RSA. Her GCS was E3V4M5. Her CT head showed left temporal contusion and left FPT acute SDH \{Fig $\mathbf{1 A}\}$. She was put on conservative treatment. After 5 days her GCS deteriorated to E2V1M4. Repeat CT showed increase in edema with brainstem compression $\{\boldsymbol{F i g} \mathbf{1 B}\}$. She was operated. Left FPT decompressive craniotomy with left temporal lobectomy done. On $4^{\text {th }}$ postoperative day her GCS improved to E4V4M6. CT head done on day 4 \{ Fig $1 C\}$ and discharged on $10^{\text {th }}$ postop day in full GCS.

brainstem $\{$ Fig $\mathbf{1 C}\}$. All the 72 patients of head injury included in our study were having moderate to severe head injury. But mainly with focal pathogenesis and definitely with variable but nonsignificant component of diffuse injury keeping in mind that the mechanism of injury involved i.e. road side accidents can produce different combination of these focal and diffuse injuries. But it was predominantly focal pathogenesis of these injuries which has resulted in good outcome of these patients. There was extrinsic compression on brainstem by SDH and frontotemporal contusions with added mass effect by edema $\{$ Fig $2 \mathbf{A}, \mathbf{B}, \mathbf{C}\}$.

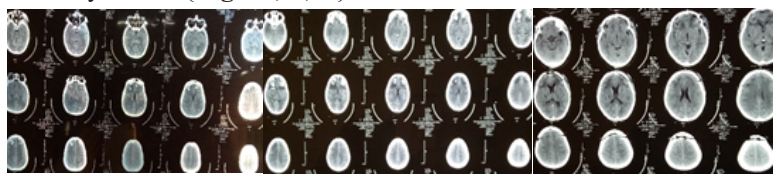

A 45 years female patient presented with history of RSA. Her GCS was E3V4M5. CT head showed bilateral frontal contusion $\{\boldsymbol{F i g} \mathbf{2 A}\}$. on $2^{\text {nd }}$ day GCS dropped to E1V1M4. Repeat CT showed in Fig 2B. She was operated and postop CT shown in Fig $2 C$. Her GCS improved to E4V5M6 on $7^{\text {th }}$ day.

Patients are selectively included in study in whom clinically neurological condition of patient is clearly explained by CT head findings. Second mechanism of injury i.e. patients with predominant diffuse injuries are not included in study. All patients included in study improved clinically and radiologically and none of patient required to undergo second procedure i.e. decompressive craniectomy. There were three patients who developed bone flap infection. Two patients required removal of bone flap and one patient managed conservatively. Five other patients developed superficial wound infection are also managed conservatively. Thirty patients developed subgaleal collection which was easily managed by percutaneous aspiration and application of crepe bandage. One patient who developed subdural hygroma was also managed by percutaneous aspiration and crepe bandage.

\section{CONCLUSION-}

Since decompressive craniectomy is double sworded procedure, it is very necessary to do it only in very selected patients with surgically nonresectable pathology to avoid complications associated with it and further need of procedures like ventriculo-peritoneal shunting and cranioplasty and complications associated with ventriculo-peritoneal shunting and cranioplasty. In patients with traumatic ICH like acute $\mathrm{SDH}$ or frontal and temporal contusions, we have found no role of DC mentioning that careful selection should be done to avoid this procedure.

\section{REFERENCES}

Honeybul neurological S, Ho KM. The current role of decompressive craniectomy in the maneybul neurological S, Ho KM. The current role of decompressive craniectomy in the management of emergencies
$10.3109 / 02699052.2013 .794974$
2. Honeybul S, Ho KM, Gillett GR. Reconsidering the role of decompressive craniectomy for neurological emergencies. J Crit Care (2017) 39:185-9. doi: 10.1016/j.jcrc.2017. 03.006

3. Rahme R, Zuccarello M, Kleindorfer D, Adeoye OM, Ringer AJ. Decompressive hemicraniectomy for malignant middle cerebral artery territory infarction: is life worth living? J Neurosurg. (2012) 117:749-54. doi: 10.3171/2012.6.JNS111140

4. Hossain-Ibrahim MK, Wasserberg J. Decompressive craniectomy-time for a change? Br JNeurosurg. (2011) 25:538-9. doi: 10.3109/02688697.2011.584641

5. Kunze, E; Meixensberger J; Janka M; Sorensen N; Roosen K (1998). "Decompressive craniectomy in patients with uncontrollable intracranial hypertension". Acta Neurochirurgica. Supplement. 71:16-18.

6. $\quad$ following decompressive for malignant swelling due to severe head injury." Journal of Neurosic de 104 (4): 469-479. di:10.3171/jn 2006.104.4.469. PMID I6619648. A Outcome Schneide, GH, Bard T, Lanksch WR, Unterberg craniectomy A (2002). Decompressive craniectomy following traumatic brain injury: ICP, CPP and neurological outcome."Acta Neurochirurgica. Supplement. 81: 77-79.

8 Malmivaara K, Kivisaari R, Hernesniemi J, Siironen J. Cost-effectiveness of decompressive craniectomy in traumatic brain injuries. Eur J Neurol. 2011;18(4): 656-62.

9 Cooper DJ, Rosenfeld JV, Murray L, et al. Decompressive craniectomy in diffuse traumatic brain injury. N Engl J Med. 2011;364(16):1493-502

10 Qiu W, Guo C, Shen H, et al. Effects of unilateral decompressive craniectomy on patients with unilateral acute post-traumatic brain swelling after severe traumatic brain injury. Crit Care. 2009;13(6):R185.

11 Flint AC, Manley GT, Gean AD, Hemphill JC, III, Rosenthal G. Post-operative expansion of hemorrhagic contusions after unilateral decompressive hemicraniectomy in severe traumatic brain injury. J Neurotrauma. 2008;25(5):503-12

12 Huang YH, Lee TC, Chen WF, Wang YM. Safety of the non-absorbable dural substitute in decompressive craniectomy for severe traumatic brain injury. J Trauma 2011;71(3):533-7.

13 Huang YH, Lee TC, Lee TH, Yang KY, Liao CC. Remote epidural hemorrhage after unilateral decompressive hemicraniectomy in brain-injured patients. J Neurotrauma 2013:30(2):96-101

14 Ho KM, Honeybul S, Lind CR, Gillett GR, Litton E Cost-effectiveness of decompressive craniectomy as a lifesaving rescue procedure for patients with severe traumatic brain injury. J Trauma. 2011;71(6):1637-44

15 Wen L, Wang H, Wang F, et al. A prospective study of early versus late craniectomy after traumatic brain injury. Brain Inj. 2011;25(13-14):1318-24.

16 Yang XF, Wen L, Shen F, et al. Surgical complications secondary to decompressive craniectomy in patients with a head injury: a series of 108 consecutive cases. Acta Neurochir(Wien) 2008;150(12):1241-7.

17 Honeybul S, Ho KM. Decompressive craniectomy for severe traumatic brain injury: The relationship between surgical complications and the prediction of an unfavourable outcome. Injury. 2014:45(9):1332-9.

18 Ban SP, Son YJ, Yang HJ, Chung YS, Lee SH, Han DH. Analysis of complications following decompressive craniectomy for traumatic brain injury. J Korean Neurosurg Soc. 2010;48(3):244-50.

19 Honeybul S, Ho KM. Long-term complications of decompressive craniectomy for head injury. J Neurotrauma. 2011;28(6):929-35. 